\title{
OPTIMAL CONTROL FOR PARTIALLY OBSERVABLE MARKOV DECISION PROCESSES OVER AN INFINITE HORIZON
}

\author{
Katsushige Sawaki \\ Nanzan University \\ and \\ Akira Ichikawa \\ University of Warwick
}

(Received August 14, 1976; Revised September 16, 1977)

\section{ABSTRACT}

In this paper we consider an optimal control problem for partially observable Markov decision processes with finite states, signals and actions over an infinite horizon. It is shown that there are $\epsilon$ optimal piecewise-linear value functions and piecewise-constant policies which are simple. Simple means that there are only finitely many pieces, each of which is defined on a convex polyhedral set. An algorithm based on the method of successive approximation is developed to compute $\epsilon$-optimal policy and $\epsilon$-optimal cost.

Furthermore, a special class of stationary policies, called finitely transient, will be considered. It will be shown that such policies have attractive properties which enable us to convert a partially observable Markov decision chain into a usual finite state Markov one.

\section{Introduction}

The partially observab].e Markov process, introduced by Dynkin [5], consists of two stochastic processes, the core process $\left\{x_{n}, n=1,2, \ldots\right\}$, which cannot directly be observed, and the signal process $\left\{s_{n}, n=1,2, \ldots\right\}$ which 
becomes known at each decision epoch $n=1,2, \ldots$. The core process is a Markov chain and the signal process is probabilistically related to the core process by the conditional probability $\gamma_{i \theta}$ of observing a signal $\theta$ given that the core process is in state $i$. Dynkin shows that the state occupancy probability represents a sufficient statistic for the complete past history. Aström [1] also considered a sjmilar model with finite states and finite actions over a finite horizon, using the method of successive approximation to find $\varepsilon$-optimal cost vectors, however, it is only applicable to problems in two dimensions. Smallwood and Sondik [8] have independently obtained similar results. Later, Sondik [9] extended this model to the inifinite horizon and introduced the class of finitely tranient policies. White [10] has considered a partially observable semi-Markov process with a finite horizon where the controller knows the times of the core process transition. Sawaragi and Yoshikawa [7] also studied the partially observable control problem with countable states states, uncountable action sets and infinite horizon, where they have explicitly showed that such partially observable models can be transformed into an ordinary complete observable one.

In this paper, under the setting of [8], we shall consider an optinal control problem with discounted cost over an infinite horizon. We introduce three concepts of simple partitions, simple policies, and piecewise linear functions. Using only these concepts we present an algorithm to find an approximation to the optimal cost function. We also show that we can construct an $\varepsilon$-optimal simple stationary policy. We are guaranteed to obtain an $\varepsilon-$ approximation of the optimal cost function in finite steps, and each step we only need to find a finite number of vectors by linear programming. Also, an application to a machine maintenance model will be discussed.

Furthermore, in this paper a special class called finite transient, of stationary policies will be considered. We shall show that such policies have very attractive properties and are useful for approximating an optimal policy. If policies are finitely transient, partially observable Markov decision processes can be reduced without loss of generality into finite state Markov decision processes with complete observation.

Sondik [9] has originally introduced the concept of finite transientness of policies for the model with finite sets of states, signals and actions over infinite horizor. However, many parts of his paper are unclear. These will be revised and clarified by giving a different definition of finitely transient policies. The same notation and symbols as in Sondik's paper are adopted here except where confusion occurs. 
2. Statement of the Probiem

Consider a Markov decision process (called the core process) with state set $\Omega=\{1,2, \ldots, N\}$, with finite action set $A$, with probability transition matrices $\left\{\mathrm{P}^{\mathrm{a}}, \mathrm{a} \varepsilon \mathrm{A}\right\}$, and with immediate cost vectors $\left\{\mathrm{q}^{\mathrm{a}}\right.$, a $\left.\varepsilon \mathrm{A}\right\}$. Let $\mathrm{X}_{\mathrm{n}}$ be the state at the $n$-th transition. Assume that the process $\left\{x_{n}, n=0,1,2, \ldots\right\}$ cannot be observed, but at each transition a signal is transmitted to the decision maker. The set of possible signals $S=\{1,2, \ldots, \theta\}$ is assumed to be finite. For each $n$, given that $x_{n}=j$ and that action $a$ is to be implemented, the signal $\theta_{n}$ is independent of the history of the signals and actions $\left\{\theta_{0}, a_{0}, \theta_{1}, a_{1}, \ldots\right.$, $\left.\theta_{n-1}, a_{n-1}\right\}$ prior to the n-th transition and has conditional probability denoted by $\gamma_{j \theta}^{a}=P\left[\theta_{n}=\theta \mid x_{n}=j, a\right]$. At time $n=0,1,2, \ldots$, let $\pi=\left(\pi_{i}\right)$ be the state probability (N-vector). For a transition probability $p^{a}=\left(P_{i j}^{a}\right)$ and an information structure $\Gamma^{a}=\operatorname{diag}\left(\gamma_{j \theta}^{a}\right)$ put $Q_{\theta}^{a}=p^{a} \Gamma_{\theta}^{a}$.

If the current state information vector is $\pi$, a signal $\theta$ is observed and action a has been chosen, then the next state information is given by

$$
T(\pi \mid \theta, a)=\frac{\pi Q_{\theta}^{a}}{\{\theta \mid \pi, a\}}
$$

where

$$
\{\theta \mid \pi, a\}=\pi Q_{\theta}^{a} \frac{\text { with }}{1}=(1, \ldots, 1)^{\mathrm{T}} .
$$

Let

$$
\pi=\left\{\pi \varepsilon R^{N}: \Sigma_{i=1}^{N} \pi_{i}=1, \pi_{i}>0 \quad \forall i\right\}
$$

We define $\Delta$ as the family of mappings $\delta: T \times \Pi \rightarrow A$ where $T=[0, \infty)$. Each element of $\Delta$ is called a policy. Given an initial distribution $\pi(0)$ and a policy $\delta$, the subsequent information vectors $\pi(n)$ form a Markov process. Our discounted control problem for an initial distribution $(0)=\pi$ is described by

$$
\min _{\delta \varepsilon \Delta} E_{\theta}\left[\sum_{n}^{\infty}=0 \beta^{n} \pi(n) q^{\delta(n, \pi(n))}\right]
$$

where $E$ is the expectation with respect to the signal, $\beta, 0 \leq \beta<1$, is the discount factor and the cost at time $n$ is given by the inner product $\pi q^{a}$ with action a. Let $C(\pi \mid \delta)$ be a cost of a stationary policy $\delta$ at an initial value $\pi$. Then it is well known (see [2], [3]) that $C(\pi \mid \delta$ ) satisfies

$$
C(\pi \mid \delta)=\pi q^{\delta}+\underset{\theta}{\beta \Sigma}\{\theta \mid \pi, \delta\} C(T(\pi \mid \theta, \delta) \mid \delta)
$$


Let $C *(\pi)$ be the optimal cost, then the following is true (see [2], [4]).

Theorem 1. There exists an optimal stationary policy $\delta *$ with $\mathrm{C}(\pi \mid \delta *)$ $=C *(\pi)$. Also, $C *(\pi)$ satisfies

$$
C *(\pi)=\min _{a \varepsilon A}\left\{\pi q^{a}+\beta \sum_{\theta \varepsilon S}\{\theta \mid \pi, a\} C *(T(\pi \mid \theta, a))\right\}
$$

for any $\pi \varepsilon \Pi$.

An $\varepsilon$-optimal cost function $\mathrm{C}$ is one satisfying

$$
\left\|C^{*}-C\right\|=\sup _{\pi \varepsilon \Pi}\left\|C^{*}(\pi)-C(\pi \mid \cdot)\right\| \leq \varepsilon
$$

A policy $\delta$ such that $\mathrm{C}=\mathrm{C}(\cdot \mid \delta)$ satisfying (4) is an $\varepsilon$-optimal policy.

For finding an $\varepsilon$-optimal policy and its cost function we define simple partitions, simple policies and piecewise (abbreviated, hereafter, by p.w.) linear functions.

Definition 1. A partition $\left\{\mathrm{v}_{i}\right\}_{i=1}^{\mathrm{m}}$ of $\Pi$ is called simple if each $\mathrm{v}_{i}$ is a convex polyhedral set, where a convex polyhedral set is the solution set of a finite system of linear inequalities, i.e.,

$$
v_{i}=\left\{\pi \varepsilon \Pi: v_{i j} \pi<0, j=1,2, \ldots, n_{i}\right\}
$$

where $v_{i j} \varepsilon R^{N}$ and $v_{i j} \pi$ is the inner product of $v_{i j}$ and $\pi$.

Remark 1: Inequalities of the form $v \pi<0$ contains those of the form $v \pi$ $<\alpha, \alpha$ scalar. In fact $v \pi<\alpha$ is equivalent to $(v-\alpha \underline{1}) \pi<0$.

Lemma 1. Let $P_{1}=\left\{\mathrm{V}_{i}\right\}$ and $P_{2}=\left\{\mathrm{W}_{j}\right\}$ be two simple partitions of $\pi$. Then, the product partition $P_{1} \cdot P_{2}=\left\{\mathrm{v}_{i} \cap \mathrm{w}_{j}\right\}$ is again simple.

Proof: Here we omit $\mathrm{v}_{i} \cap \mathrm{w}_{j}$ if $\mathrm{v}_{i} \cap \mathrm{w}_{j}=\phi$. The sets $\mathrm{v}_{i} \cap \mathrm{w}_{i}$ are disjoint and are convex polyhedral sets. Hence $P_{1} \cdot P_{2}$ is simple.

Definition 2. A stationary policy $\delta$ is called simple with respect to a simple partition $\left\{v_{i}\right\}$ if $\delta(\pi)=a_{i}$ on $v_{i}, i=1,2, \ldots, m$.

Definition 3. A real valued function $f$ on $I$ is called piecewise linear if $f(\pi)=f_{i} \pi$ on $v_{i}, i=1,2, \ldots, m$, where $\left\{v_{i}\right\}$ is a simple partition and $f_{i}$ $\varepsilon R^{N}$.

Example: Define an information structure as a mapping from the set of 
states (unobservable) of the core process to the set of distinctive signals $\theta$. The decision maker chooses an information structure from the set of available structures and decides upon an action for the system.

Let $a=\left(a_{1}, a_{2}\right)$ be the pair of actions, $a_{1}$ for the system control and $a_{2}$ for information acquisition. More precisely, we have

$$
\begin{aligned}
& P_{i j}^{a}(\theta)=P_{i j}^{a_{1}} \gamma_{j \theta}^{a_{2}} \\
& \pi q^{a}=\sum_{i=1} \pi_{i} \sum_{j=1} P_{j j}^{a_{1}} \sum_{\theta=1}^{\theta} \gamma_{j \theta}^{a_{2}} q\left(i, j, \theta, a_{1}, a_{2}\right)
\end{aligned}
$$

where $q\left(i, j, \theta, a_{1}, a_{2}\right)$ is the jmmediate cost of the core process when a state of the core process moves from $i$ to $j$ and a signal $\theta$ observed under actions $a_{1}$ for the system and $a_{2}$ for the information structure, and $\pi=\left(\pi_{1}, \ldots, \pi_{N}\right)$ is the probability vector with an interpretation $\pi_{i}$ is the probability that the core process is in state $i$.

Consider a machine maintenance and repair model (e.g., Smallwood and Sondik [8]) as an application of partially observable models. But this model is a modification of Smallwood and Sondik's. The machine consists of two internal components. The states of the core process $x_{n}=i, i=1,2,3$, have the following interpretation. If $i=1$, then both components are broken down, if $=2$ either one is broken down and if $i=3$ both of them are working. Assume that the machine produces $M$ finished products at each period and the machine cannot be inspected. The actions $a_{1}$ for the machine control are to repair and not to repair the machine. The actions $a_{2}$ for information acquisition are the numbers of a sample to choose out of the $M$ finished products. The signals $\theta$ are the number of defective products in the sample, which forms the signal process $\left\{\theta_{n}, n=1,2, \ldots\right\}$. The core process $\left\{x_{n}, n=1,2, \ldots\right\}$ is the unknown states of the components of the machine. Let $\pi_{i}=P\left\{X_{n}=i\right\}, i=1,2,3$ and put $\pi$ $=\left(\pi_{1}, \pi_{2}, \pi_{3}\right)$. Then, the process $\left\{\left(x_{n}, \theta_{n}\right), n=1,2, \ldots\right\}$ becomes a partially observable machine maintenance and repair model with actions $a=\left(a_{1}, a_{2}\right)$ and immediate cost $\pi q^{a}$.

\section{Finitely Transient Policies}

In this section a special. class of simple stationary policies, called finitely transient, will be studied. The class of such policies has very attractive properties even though all stationary policies do not belong to such. a class.

Define, for a simple policy $\delta$, 


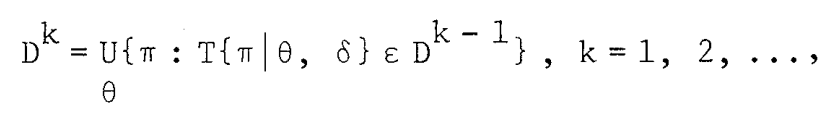

where $\mathrm{D}^{0}=\mathrm{UD}_{i}^{0}=U\left\{\pi \varepsilon \Pi: \mathrm{v}_{i j}{ }_{i}=0\right\}$ which forms the boundary set of the partition $\left\{V_{i}\right\}$ corresponding to a simple policy $\delta$. Let $V^{k}=\left\{V_{j}^{k}\right\}_{j=1}^{m}$ be the collections of sets whose boundaries are $\mathrm{U}_{\mathrm{L}}^{\mathrm{U}}{ }_{0} \mathrm{D}^{\mathrm{L}}$ and then $\mathrm{V}^{\mathrm{k}^{\mathrm{k}}}$ is a refinement of $\mathrm{V}^{\mathrm{k}-1}, \mathrm{k} \geq 1$, where $V^{0}=\left\{V_{j}\right\}$.

Definition 4. A simple policy \& is called finitely transient if there is an integer $k<\infty$ such that

$$
T\left(V_{j}^{k} \mid \theta, \delta\right) \subset V_{v(j, \theta)}^{k} \quad \text { for al1 } \ni
$$

where $T(V \mid \theta, \delta)=\{\mathrm{T}(\pi \mid \theta, \delta): \pi \varepsilon V\}$ and $v(j, \theta)$ is the index of the set containing $\mathrm{T}\{\pi \mid \theta, \delta\}$ for $\pi \varepsilon \mathrm{V}_{j}^{\mathrm{k}}$. Let $\mathrm{k}_{\delta}$ be the smallest such integer.

Lemma 2. $D^{k}=\phi$ for all $k \geq k_{\delta}$ if and only if $\delta$ is finitely transient with the index $k$.

Proof: Suppose that $\delta$ is finitely transient with the index $k_{\delta}$, that is,

$$
\left.T\left(V_{j}^{k} \mid \theta, \delta\right) \subset v_{v(j,}^{k}, \theta\right) \text { for all } \theta
$$

$\mathrm{D}^{\mathrm{k}_{\delta}}=\phi$ because $\mathrm{T}\left(\mathrm{V}_{\mathrm{j}}{ }^{\mathrm{k}} \mid \theta, \delta\right)$ is the set of all possible state information at the $k_{\delta}$-th period and $\Gamma_{i} k$ is open in $\Pi$ for all, $i, k$. Let $L_{\delta}$ be the set function defined as $L_{\delta}(B)=\underset{\theta}{U}\{\pi: T(\pi \mid \theta, \delta) \varepsilon B\}$

$$
\begin{aligned}
D^{k} & =\underset{\theta}{U}\left\{\pi: T(\pi \mid \theta, \delta) \varepsilon D^{k-1}\right\} \\
& =L_{\delta}\left(D^{k-1}\right) \\
& =L_{\delta}^{k}\left(D^{0}\right)
\end{aligned}
$$

If $D^{k}=L_{\delta}^{k}\left(D^{0}\right)=\phi$, then

$$
1^{\mathrm{k}+1}=L_{\delta}(\phi)=\phi
$$

Hence, by induction $\mathrm{D}^{\mathrm{k}}=\phi$ for all $\mathrm{k} \geq \mathrm{k}_{\delta}$.

Conversely, suppose that $D^{k}=\phi$ for $a 11 k \geq k$ and that 


$$
\mathrm{T}\left(\mathrm{V}_{j}^{\mathrm{k}} \mid \theta, \delta\right) \not \subset \mathrm{V}_{v(j, \theta)}^{\mathrm{k}} \text { for some } \theta
$$

So, there exist $\pi^{1}, \pi^{2} \varepsilon V_{j_{k}}^{k}$ such that for some $\theta T\left(\pi^{1} \mid \theta, \delta\right)$ and $T\left(\pi^{2} \mid \theta\right.$, $\left.\delta\right)$ do not belong to the same set ${ }_{V}^{j}(j, \theta)$.

Then, there is a constant $\lambda, 0<\lambda<1$, such that $\lambda^{-\top} T^{\prime}\left(\pi^{1} \mid \theta, \delta\right)+\left(1-\lambda^{-}\right)$

$\mathrm{T}\left(\pi^{2} \mid \theta, \delta\right) \varepsilon \mathrm{D}^{\mathrm{k}}$ and $\lambda^{\prime}$ is given by $\lambda^{\prime}=\lambda \pi^{i} \mathrm{Q}_{\theta}^{\mathrm{a}} / \pi \mathrm{Q}_{\theta}^{\mathrm{a}} \cdot \lambda^{\prime} \mathrm{T}\left(\pi^{\mathrm{l}} \mid \theta, \delta\right)+\left(1-\lambda^{\prime}\right) \mathrm{T}\left(\pi^{2} \mid \theta, \delta\right)$ $=\mathrm{T}\left(\lambda \pi^{1}+(1-\lambda) \pi^{2} \mid \theta, \delta\right)$. By letting $\pi=\lambda \pi^{1}+(1-\lambda) \pi^{2}, \mathrm{~T}(\pi \mid \theta, \delta) \varepsilon \mathrm{D}^{\mathrm{k}}$ which is a contradction.

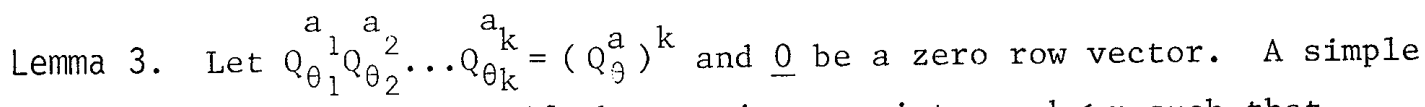
policy $\delta$ is finitely transient if there exists an integer $k<\infty$ such that

$$
V_{i j}\left(Q_{\theta}^{a}\right)^{k}>\underline{0} \text { or }<\underline{0} \text { for all } \theta, a, i, j .
$$

Proof:

$$
\begin{aligned}
D^{k}= & U\left\{\pi: T(\pi \mid \theta, \delta) \varepsilon D^{k-1}\right\} \\
= & \quad U \underset{i, j}{U}\left\{\pi: v_{i j}\left(Q_{\theta}^{a}\right)^{k} \pi=0\right\}
\end{aligned}
$$

Since $\pi_{i} \geq 0$ and $\Sigma_{i} \pi_{i}=1, D^{k}:=\phi$ if $v_{i j}\left(Q_{\theta}^{a}\right)^{k}>\underline{0}$ or $\underline{0}$ for all $\theta, a, i, j \cdot$ By Lemma 2, this completes the proof.

Remark 1. In Lemmas 2 and 3 , the assumption concerning $\delta$ being simple is crucial. A counter example is presented as follows: suppoese that there are only two states $\mathrm{N}=2$ and $\pi_{2}=1-\pi_{2} \geq 0$.

Define,

$$
\delta\left(\pi_{1}\right)=\left\{\begin{array}{l}
a_{1} \text { if } \pi_{1} \text { is rational } \\
a_{2} \text { otherwise }
\end{array}\right.
$$

which is stationary but not simple. Then $D^{\delta}$ is the uncountable discontinuous set which never becomes empty. Therefore, a finitely many partition $\{\mathrm{V}\}$ does not exist.

Theorem 2. Let $\delta$ be a simple policy. Then, the following are equivalent.

(i) $\delta$ is finitely transient with the index $\mathrm{k}_{\delta}$.

(ii) $C(\pi \mid \delta)$ is piecewise linear.

Proof of $[(i) \rightarrow($ ii $)]:$ Suppose that we have a finitely many partition $\mathrm{V}^{\mathrm{k}}$ $=\left\{V_{j}^{k}\right\}$ for $k \geq k_{\delta}$. Let $\bar{C}(\pi \mid \delta)=\pi \alpha_{j}, \pi \varepsilon V_{j}^{k}$ and $\left.\alpha_{j}=q^{j}+\beta \varepsilon_{\theta}{ }_{\theta}^{j} \alpha_{v(j,}, \theta\right)$

$$
\bar{C}(\pi \mid \delta)=\pi \alpha_{j}, \pi \varepsilon V_{j}^{k}
$$




$$
\begin{aligned}
& =\pi\left(q^{a^{j}}+\beta \sum_{\theta} Q_{\theta}{ }^{j} \alpha_{\nu}(j, \theta)\right) \\
& =\pi q^{\delta}+\beta \Sigma\left\{\pi \mid \theta, \frac{\delta\} Q_{\theta}^{\delta}}{\{\pi \mid \theta, \delta\}} \alpha_{\nu(j, \theta)} \text { for a.l } \pi \varepsilon v_{j}^{k}\right. \\
& =\pi q^{\delta}+\underset{\theta}{\beta \sum\{\pi \mid \theta, \delta\} T(\pi \mid \theta, \delta) \alpha_{\nu}(j, \theta)} \text { for } \delta \text { finitely transient } \\
& =\pi q^{\delta}+\underset{\theta}{\beta \Sigma\{\pi \mid \theta, \delta\} \bar{C}(T(\pi \mid \theta, \delta) \mid \delta)} \\
& \equiv\left(U_{\delta} \bar{C}\right)(\pi)
\end{aligned}
$$

Since $C(\cdot \mid \delta)$ is the unique solution of $\mathrm{U}_{\delta}, \mathrm{C}(\cdot \mid \delta)=\overline{\mathrm{C}}(\cdot \mid \delta)$.

Proof of $[($ ii $) \rightarrow(i)]$ : From piecewise linearity of $C(\cdot \mid \delta)$, we have $C(\pi \mid \delta)$ $=\pi \alpha_{j}$ for $\pi \varepsilon v_{j}^{k}$ with the partition $\left\{v_{i}^{k}\right\}$ for $k \geq k$ and $\delta(\pi)=a_{j}, \pi \varepsilon v_{j}^{k}$.

So $C(T(\pi \mid \theta, \delta) \mid \delta)=T(\pi \mid \theta, \delta) \alpha_{\nu(j, \theta)}$ for $\pi \varepsilon v_{j}^{k}$.

Then, we must have $T(\pi \mid \theta, \delta) \varepsilon V_{v(j, \theta)}^{k}$ for all $\pi \varepsilon v_{j}^{k}$ and all $\theta$. So

$$
\mathrm{T}\left\{\mathrm{V}_{j}^{\mathrm{k}} \mid \theta, \delta\right\} \subset \mathrm{v}_{v(j,}^{\mathrm{k}}, \quad \text { for all } \theta \text {. }
$$

Corollary: If a policy $\delta$ is finitely transient with the simple partition $\left\{\mathrm{V}_{j}\right\}$, then its cost $\mathrm{C}(\pi \mid \delta)$ can be computed by solving the following equations;

$$
C(\pi \mid \delta)=\pi \alpha_{j} \text { for } \pi \varepsilon v_{j}, j=1,2, \ldots, m
$$

and

$$
\alpha_{j}=q^{a}{ }^{j}+\beta \sum_{\theta} Q_{\theta}{ }^{j} \alpha_{\nu(j, \theta)}, j=1,2, \ldots, m .
$$

The proof immediately follows from Theorem 1. Note that the set of equations (7) has a unique bounded solution (see Appendix) and that $m$ need not be equal to the number of actions.

\section{Properties of $U_{a}$ and $U_{*}$}

This section is a study of the properties of $U_{a}$ and $U_{*}$. Most of these properties will be used later in the development of the algorithm to find $\varepsilon-$ optimal approximations to $C^{*}$ and $\delta *$. 
Let $F$ be the space of real valued functions on $\pi$ with sup norm. Then $F$ is a Banach space (B-space). Let II be equipped with the Euclidean norm, and let $\mathrm{C}$ be the subset of continuous functions in $\mathrm{F}$. Then $\mathrm{C}$ is a closed linear subspace (hence is itself a B-space) of F. Define operators $U_{a}, U_{*}$ on $F$ by

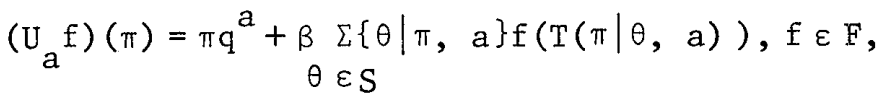

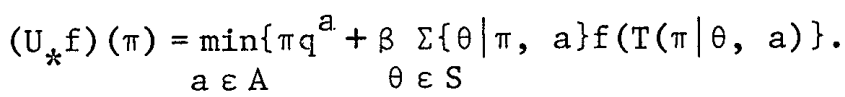

Lemma 4. (i) $\mathrm{U}_{a}, \mathrm{U}_{*}$ are contraction mappings with contraction coefficient $\beta$.

(ii) $\mathrm{U}_{a}, \mathrm{U}_{*}$ are monotone, i.e., if $\mathrm{f}, \mathrm{g} \varepsilon \mathrm{F}$ with $\mathrm{f} \leq \mathrm{g}$, then $\mathrm{U}_{*} \mathrm{f}$ $\leq \mathrm{U}_{*} \mathrm{~g}$ and $\mathrm{U}_{\mathrm{a}} \mathrm{f} \leq \mathrm{U}_{\mathrm{a}} \mathrm{g}$.

(iii) They map $C$ into itself, thus fixed points of these operators are continuous functions.

Proof: The properties (i), (ii) are standard. (See [2], [6]). (iii) $\mathrm{U}_{\mathrm{a}}$ clearly maps $C$ into self. $\left(U_{*} f\right)(\pi)$ is the minimum of finite number of continuous, hence it is also continuous, provided $f$ is continuous.

From Lemma 4 we get some information on $C^{*}$ and $\delta^{*}$.

Lemma 5. The fixed point of $\mathrm{U}_{*}$ exists and is the optimal cost function $\mathrm{C}^{*}$, which is continuous.

Before stating our main results, we need two lemmas.

Lemma 6. Let $f$ be a piecewise linear function w.r.t. $\left\{v_{i}\right\}$ on $\Pi$. Define a stationary policy $\delta_{f}$ by $U_{*} f$, namely, $\delta_{f}(\pi)=a_{i}$ if $a_{i}$ minimizes ( $\left.U_{a} f\right)(\pi)$. Then $\delta_{f}$ is simple.

Proof: Let $\left\{\mathrm{V}_{i}\right\}$ be the simple partition for $f$. Define

$$
V_{i}(a, \theta)=\left\{\pi \varepsilon \pi: T(\pi \mid \theta, a) \varepsilon V_{i}\right\}
$$

Then for each a, $\theta,\left\{V_{i}(a, \theta)\right\}$ i.s a simple partition. In fact $V_{i}(a, \theta)$ is given by

$$
\frac{\pi Q_{\theta}^{a} v_{i j}}{\{\theta \mid \pi, a\}}<0, j=1,2, \ldots, n_{i},
$$

or equivalently,

$$
\pi Q_{\theta}^{a} V_{i j}<0, j=1,2, \ldots, n_{i},
$$


where $v_{i j}$ characterizes $V_{i}$. Let $\left\{v_{i, \theta}^{a}\right\}$ be a simple partition defined by $\cap_{i, \theta} V_{i}(a, \theta)$ (see Lemma 1 ), then $U_{a} f$ is linear on each $V_{i, \theta}^{a}$ More precisely,

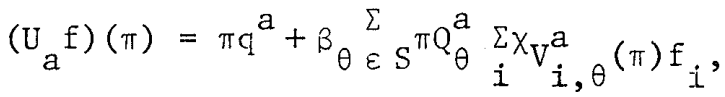

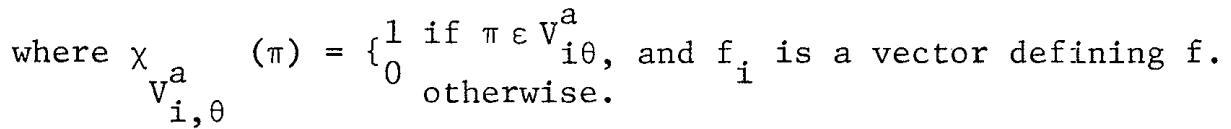

Since $\delta$ is defined by minimizing finite number of piecewise linear functions, it is simple.

Lemma 7. (i) If $f$ is piecewise linear, then $U_{*} f$ is piecewise linear. (ii) If $f$ is concave, then $U_{*} f$ is also concave.

Proof: $U_{a} f$ has the same property as $\mathrm{f}^{\prime} \mathrm{s}$. By the definition of $\mathrm{U}_{*} \mathrm{f}$, the desired results are obtained.

Theorem 3. Let $f_{0} \varepsilon F$, and define

$$
\mathrm{f}_{\mathrm{n}}(\pi)=\left(\mathrm{U}_{*} \mathrm{f}_{\mathrm{n}-1}\right)(\pi)
$$

Let $\delta_{n}$ be the decision rule at stage $n$ defined by $U_{*} f_{n-1}$.

(i) $f_{\mathrm{n}}$ converges to $\mathrm{C} *$.

(ii) If $\mathrm{f}_{0}$ is piecewise linear, then so is $\mathrm{f}_{\mathrm{n}}$ for any $\mathrm{n}$. Furthermore, $\delta_{\mathrm{n}}$ is simple.

(iii) If $\mathrm{f}_{0}$ is concave, then $\mathrm{f}_{\mathrm{n}}$ is concave.

(iv) If $\mathrm{f}_{1} \leq \mathrm{f}_{0}$, then $\mathrm{f}_{\mathrm{n}} \downarrow \mathrm{C}^{*}$. If $\mathrm{f}_{1} \geq \mathrm{f}_{0}$, then $\mathrm{f}_{\mathrm{n}} \uparrow \mathrm{C} *$.

Proof: The assertions follow from Lemmas 4, 5, 6 and 7 .

Remark 2. If we take $f_{0}(\pi)=C(\pi \mid \delta)$ for some stationary policy $\delta$, then $\mathrm{f}_{\mathrm{n}}+\mathrm{C}^{*}$. In particular, if we take $\delta(\pi)=$ a for all $\pi$, thus $C(\pi \mid \delta)=\mathrm{f}_{0}(\pi)=$ $\pi\left(I-\beta P^{a}\right)^{-1} q^{a}$, then $f_{n}$ is continuous concave and piecewise linear and $f_{n} \downarrow C^{*}$. Hence $C *$ is continuous and concave.

Remark 3. Let $\mathrm{f}_{0}(\pi)=\min \pi \mathrm{q}^{\mathrm{a}}$, then $\mathrm{f}_{0}$ is piecewise 1inear, concave and continuous. Hence (ii) and (iii) hold. Since $\mathrm{f}_{\mathrm{n}}$ corresponds to the optimal cost for the n-period problem with discounting, this case is essentially equivalent to the results in [9]. If we further assume $\mathrm{q}^{\mathrm{a}} \geq 0$ for any $a \mathrm{~A}$, then $\mathrm{f}_{\mathrm{n}} \uparrow \mathrm{C}^{*}$.

Next we shall discuss the rate of convergence.

Lemma 8. Let $\mathrm{f} \varepsilon \mathrm{F}$. If || $\mathrm{f}-\mathrm{U}_{*} \mathrm{f} \| \leq(1-\beta) \varepsilon$, then || $\mathrm{C}^{*}-\mathrm{f}|| \leq \varepsilon$. 
Proof: ||$C^{*}-\mathrm{f}\left\|\leq|| \mathrm{U}_{*} \mathrm{C}^{*}-\mathrm{U}_{*} \mathrm{f}||+|| \mathrm{U}_{*} \mathrm{f}-\mathrm{f}\right\|$

$$
\leq \beta|| C^{*}-f||+|| U_{*} f-f \| \text {. }
$$

After arranging, the result is obtained.

Theorem 4. If $\beta^{n}|| f_{0}-U_{*} f_{0}|| \leq(I-\beta) \varepsilon$, then ||$C^{*}-f_{n} \| \leq \varepsilon$.

Proof: Since we have

$$
\begin{aligned}
\| f_{n}-U_{*} f n|| & =\left\|U_{*} f_{n-1}-U_{*}^{2} f_{n-1}\right\| \\
& \leq \beta|| f_{n-1}-U_{*} f_{n-1} \| \\
& \cdot \\
& \cdot \\
& \cdot \\
& \leq \beta^{n}|| f_{0}-U_{*} f \|
\end{aligned}
$$

the theorem follows directly from Lemma 8.

Remark 4. If we calculate ||$f_{0}-U_{*} f_{0} \|$, then Theorem 4 tells us when to stop. Furthermore, at each step $n$ we know from ||$f_{n}-U_{*} f_{n} \|$ how many steps (at most) we have to go after the step n.

\section{Algorithm}

Since $\pi$ is uncountable, it is far from trivial to calculate $C(\pi \mid \delta)$ which may not be a piecewise linear funciton of $\pi$, except the case that $\delta$ is finitely transient. In this section we shall approximate $C(\pi \mid \delta)$ by using the method of successive approximation.

The method of successive approximation is a well known and popular method for solving equations. The method is to start with a cost function $f_{0}$, and to iterate $U_{*}$, constructing a sequence of cost functions $f_{n}=U_{*} f_{n-1}, n=1,2, \ldots$ By Lemma $4, U_{*}$ is a contraction mapping with fixed point $\mathrm{C}^{*}$ and by Theorem 3 , $\left\{f_{n}\right\}$ converges to $C^{*}$. By Theorem 4, $n$ can be chosen sufficiently large, so that $\mathrm{f}_{\mathrm{n}}$ is an $\varepsilon$-optimal cost function. In fact by taking logarithms of the expression in Theorem 4,

$$
\mathrm{n}>\log \left[\frac{(1-\beta) \varepsilon}{|| f_{0}-f_{1} \|}\right] / \log \beta
$$

is adequate. 
The next theorem provides a means of constructing an $\varepsilon$-optimal policy from an $\varepsilon^{\prime}$-optimal cost function and specifies the relationship between $\varepsilon$ and $\varepsilon^{\prime}$. The algorithm will first construct an $\varepsilon$-optimal cost function. From this cost function, an $\varepsilon$-optimal policy is constructed.

Let $f_{0}$ be piecewise linear, and let $\delta_{n}$ be defined by $U_{*} f_{n-1}$, i.e., $\delta_{n}(\pi)=a_{1}$ if $a_{1}$ minimizes $\left(U_{a} f_{n-1}\right)(\pi)$. Then $\delta_{n}$ is simple, and satisfies $\mathrm{U}_{*} \mathrm{f}_{\mathrm{n}-1}=\mathrm{U}_{\delta_{\mathrm{n}}} \mathrm{f}_{\mathrm{n}-1}$, where $\mathrm{U}_{\delta}$ for a stationary policy $\delta$ is defined by

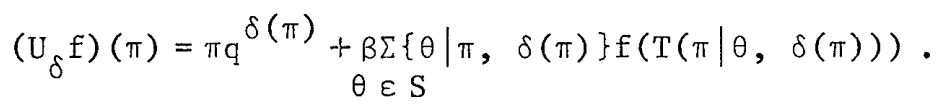

Theorem 5. If ||$C^{*}-\mathrm{f}_{\mathrm{n}-1}|| \leq \frac{1-\beta}{2 \beta} \varepsilon$, then ||$C *-C\left(\cdot \mid \delta_{\mathrm{n}}\right)|| \leq \varepsilon$.

Proof: It is easy to show that $U_{\delta}$ for any stationary policy $\delta$ is a contraction mapping and that the fixed point is $C(\cdot \mid \delta)$, i.e., $C(\pi \mid \delta)=U_{\delta} C(\cdot \mid \delta)(\pi)$. Consider

$$
\begin{aligned}
& || C *-C\left(\cdot \mid \delta_{n}\right)||=|| U_{\delta_{n}} C\left(\cdot \mid \delta_{n}\right)-U_{*} C *|| \\
& \leq|| U_{\delta_{n}} C\left(\cdot \mid \delta_{n}\right)-U_{\delta_{n}} C^{*}||+|| U_{\delta_{n}} C^{*}-U_{\delta_{n}} f_{n-1}|| \\
& +|| \mathrm{U}_{*} \mathrm{f}_{\mathrm{n}-1}-\mathrm{U}_{*} \mathrm{C} * \mid \\
& \leq \beta|| C\left(\cdot \mid \delta_{n}\right)-C * \|+\beta|| C *-f_{n-1}||+\beta|| f_{n-1}-C *|| .
\end{aligned}
$$

Here we used the equality $\mathrm{U}_{*} \mathrm{f}_{\mathrm{n}-1}=\mathrm{U}_{\delta_{\mathrm{n}}} \mathrm{f}_{\mathrm{n}-1}$. Rearranging the above inequality we obtain

$$
(1-\beta)|| C\left(\cdot \mid \delta_{n}\right)-C^{*}|| \leq 2 \beta|| C *-f_{n-1}|| \leq(1-\beta) \varepsilon
$$

Hence ||$C\left(\cdot \mid \delta_{n}\right)-C *|| \leq \varepsilon$.

If the state space is uncountable, or even countably infinite, then this procedure is difficult to implement on a computer. However, since the partially observable Markov decision process has the structure of piecewise linearity and $f_{0}$ is p.w. linear, then each $f_{n}$ is p.w. linear and each $\delta_{n}$ constructed as in the previous theorem is simple (by Lemma 6). In this case, the cost functions and policies can be specified by a finite number of items - the inequalities describing each cell of a simple partition and the corresponding action or linear function. 
Algorithm to Find an E-optimal Simple Policy:

(i) Start with any p.w. linear function $f_{0}$

(ii) Compute $f_{1}=U_{*} f_{0}$.

(iii) Choose an integer $n$ such that

$$
\beta^{n}|| f_{0}-f_{1} \| \leq(1-\beta) \varepsilon^{\prime},
$$

where $\varepsilon^{\prime}=(1-\beta) \varepsilon / 2 \beta$. I.e., choose $\hat{n}$ larger than

$$
\log \left[\frac{(1-\beta)^{2} \varepsilon}{2 \beta|| f_{0}-f_{1} \|}\right] / \log \beta \text {. }
$$

(iv) Compute $\mathrm{f}_{\mathrm{n}}=\mathrm{U}_{*} \mathrm{f}_{\mathrm{n}-1}$ successively until $\mathrm{n}=\hat{\mathrm{n}}$.

(v) Consequently, we obtain $f_{\hat{n}}$ such that

$$
\left\|C^{*}-f_{\hat{n}}\right\| \leq \varepsilon^{\prime} .
$$

(vi) Construct a policy is satisfying

$$
U_{\delta} f_{\hat{n}}=U_{*} f_{\hat{n}} \cdot
$$

Then $\delta$ is $\varepsilon$-optimal.

Remark 5. The algorithm can be started with $f_{0} \equiv 0$.

Remark 6. The termination criterion, $\mathrm{n}=\hat{\mathrm{n}}$, in the algorithm has the advantage that $\left\|f_{0}-f_{1}\right\|$ is computed only once. However, it has the disadvantage that $\hat{n}$ will probably be larger than necessary, causing unnecessary

\section{iterations.}

An alternative would be to compute $\left|f_{n}-f_{n-1}\right| \mid$ at each iteration and stop whenever $\left\|f_{n}-f_{n-1}\right\| \leq(1-\beta) \varepsilon^{\prime} / \beta$. Theorem 2 guarantees that $f_{n}$ is an $\varepsilon^{\prime}-$ optimal cost function. However, the computations of $\mid f_{n}-f_{n-1} \|$ will, in general, be expensive.

The best procedure is undoubtedly to check $\left|f_{n}-f_{n-1}\right| \mid$ at some, but not all, iterations. For example, $\hat{n}$ might be computed based on $\left|f_{0}-f_{1}\right| \mid$. Then at some iteration $n$ near $\frac{\hat{n}}{2}$, recompute $n$ based on ||$_{n}-f_{n-1}||$. 


\title{
Acknowledgment
}

The authors wish to thank Professors S. Brumelle and U. Haussmann, University of British Columbia, for their useful comments and discussions. Also worthy of acknowlwdgment is the very helpful review of one of the referees. We wish to thank him or her for the many comments. Also, special thanks go to Professor Y. Iihara, Nanzan University, for his encouragement and helpful suggestions.

\section{References}

[1] K.J. Aström, Optimal Control of Markov Process with Incomplete State Information, J. Math. Anal. App., 10, $174-205$ (1965).

[2] D. Blackwell, Discounted Dynamic Programming, Ann. Math. Sta., 36, 226 235 (1965) .

[3] E.V. Denardo, Contraction Mapping in the Theory Underlying Dynamic Progrmming, SIAM Review, 9, $165-177$ (1967).

[4] M.H. Davis and P. Varaiya, Dynamic Programming Conditions for Partially Observable Stochastic System, SIAM J. Control 11, $226-261$ (1973).

[5] E.B. Dynkin, Controlled Random Sequences, Theory of Probability and Its Applications, X, 1 - 14 (1965).

[6] S.M. Ross, Applied Probability Models with Optimization Applications, Holden Day, 1970.

[7] Y. Sawaragi and T. Yoshikawa, Discrete-Time Markovian Derision Process with Incomplete State Observation, Ann. of Math. Stat., 41, 78-86 (1970).

[8] R.D. Smallwood and E.J. Sondik, Optimal Control of Partially observable Processes over the Finite Horizon, Opns. Research 21, 1071-1088 (1973)

[9] E.J. Sondik, The Optimal Control of Partially Observable Markov Processes over the Infinite Horizon: Discountec Costs, Department of EngineeringEconomic Systems, Stanford University, California, May 1975.

[10] C.C White, Procedures for the Solution of a Finite Horizon, Partially Observed, Semi-Markov Optimization Problem, Oper. Research, 24, $348-358$ (1976)

\author{
Katsushige SAWAKI \\ Faculty of Business Administration \\ Nanzan University \\ 18, Yamazato-cho \\ Showa-ku, Nagoya, 466 \\ Japan
}




\section{Appendix}

Lemma: The set of linear equations given by

$$
\alpha j=q^{a}+\beta \sum Q_{\theta}{ }^{a}{ }_{\alpha(j, \theta)}, j=1,2, \ldots, m \text {, }
$$

has a unique bounded solution.

Proof: Let $a_{j}=j$ for each $j$.

We may set $Q_{\theta}^{j} \alpha_{v(j, \theta)}=\tilde{Q}_{i}^{j}{ }_{i}$ if $v(j, \theta)=i, i=1,2, \ldots, \mathrm{m}$.

Then we have

$$
\alpha_{j}=q^{j}+\beta \tilde{Q}_{1}^{j} \alpha_{1}+\ldots+\beta \tilde{Q}_{m}^{j}{ }_{\alpha}
$$

Let

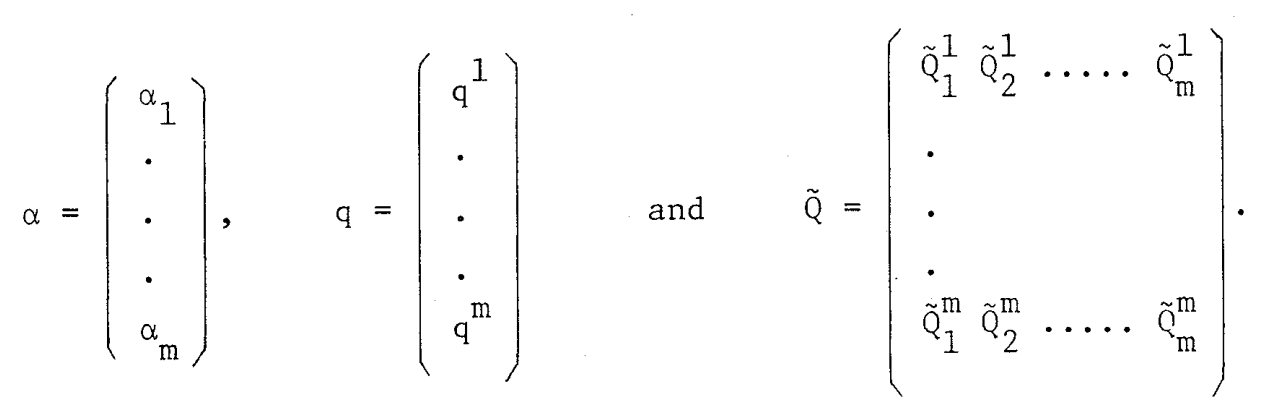

Hence, we obtain

$$
\alpha=\mathrm{q}+\beta \tilde{Q} \alpha \text {, that is; } \alpha=(I-\beta \tilde{Q})^{-1} \mathrm{q}
$$

where since ||$\beta Q||<1$ for $0 \leq \beta<1$ with the sup norm, there exists $(I-\beta \tilde{Q})^{-1}$. 


\section{アブストラクト \\ 部分観測可能なマルコフ決定過程とアルゴリスム}

南山大学沢木勝茂
ウォーリック大学市川 朗

この論文では、システムの現在の状態を直接に観測することは許されず，システムの内部機構より 発生される信号によってシステムの現在の状態に対する部分的なあるいは不完全な情報に基づくマル コフ決定過程について論述する。システムの状態を直接に観測して完全情報を得ることは，一般に高 価でありまた物理的困難を伴なう場合が多いから，このような不完全情報の下でのマルコフ決定過程 を考察することはより現実的であるし，また在庫管理，機械保全，待ち行列などの経営科学に打ける 種々のモデルへの応用を可能にさせる。

ここでは，状態，信号拉よび行動が有限個の集合からなり無限期間の最適制御モデルを動的計画法 によって公式化し，最適政策と最適費用に対する近似解を遂次近似法によって計算するためのアルゴ リスムを提示する。主要な結果は，最適政策に対する近似解として区分的定数な定常政策が存在する ことと，最適費用に対する近似解として区分的線形な費用関数が存在することである。この結果から アルゴリスムはたかだか線形関数の繰作を含むこと，従って線形計画法の範囲内にとどまることが明 示される。このモデルでは動的計画法の状態変数が確率べクトルとなって。その集合はもはや有限で あ無限加算個であなくなり，連続体となる。従来の動的計画法はその状態変数が連続なモデルに対し て実行可能な解法として一般に機能しないから，われわれのアルゴリスムは同時に連続変数をあつ動 的計画法の解法を与えることになる。

更に, 定常政策の特別なクラス (有限過度的政策) の概念を導入し，このクラスの政策がどんな構 造とその長所を有しているか論述する。この有限過度的政策の下では, 部分観測可能なマルコフ過程 から通常の有限状態のマルコフ過程への変換が可能となり,そこでは近似解ではなく正確な最適解を 得ることが可能となる。 